\title{
ARE THE INVESTORS OF ISLAMABAD STOCK EXCHANGE (ISE) SUFFERING FROM BEHAVIORAL BIASES(OVERCONFIDENCE, ANCHORING, AND \& CONFIRMATION BIAS)?
}

\author{
Bilal A.Abbasi \\ Dr. Syed Muhammad Amir Shah \\ Department of Leadership and Management Studies, \\ National Defence University,Islamabad, Pakistan
}

Doi: 10.19044/elp.v1no2a3 URL:http://dx.doi.org/10.19044/elp.v1no2a3

\begin{abstract}
Traditional finance theories assume that investors are rational, whereas, the behavioral finance research contends that investors suffer from psychological biases, which affect their decision making process. In this paper we will check the rationality of investors of Islamabad Stock Exchange (ISE). For this purpose, we have identified three core psychological factors (Overconfidence, Anchoring, and Confirmation bias) of an individual, which are central to human decision making process. The presence of these behavioral biases among the investors of ISE got confirmed with help of frequency and percentage.
\end{abstract}

Keywords: Rationality, Behavioral Biases

\section{Introduction}

Traditional finance theories assume that investors are rational.This rational approach expects that investor generates different alternatives and selects an alternative which best suits the decision making situation. In other words, the investor tries to reach optimum decision and maximum efficiency by using all available information. Whereas, the behavioral finance research contends that investors suffer from psychological biases, which affect their decision making process.Behavioral Finance, evolve as recognized field within the broad boundaries of finance advocated by renowned people of the area. For instance the bubbles and crashes of financial world in year 2008 can be explained to a certain extent with the help of traditional financial models. Ball (2009), in his paper on the global financial crisis argued that the crumple of Lehman Brothers and other large financial institutions, far from 
resulting from excessive faith in efficient markets, reflects a failure to notice the lessons of efficient markets. To grasp their underpinning completely, one need to understand the psychology of the market players; because it helps to explain the irrational behavior of the investors.

Kahneman and Riepe (1998) in their paper titled "Aspects of Investor Psychology" argue that investors do not accurately judge their cognitive and emotional weaknesses relating to the investment decisions. This results in faulty assessment of their own interests and true wishes, the relevant facts that they tend to ignore, and the limits of their ability to accept advice and to live with the decisions they make. In such scenario, the investor suffers from biases of judgment or decision making, also called cognitive illusion. The cluster of related biases and cognitive illusions in intuitive judgment that are most likely to affect investment decisions, includes (1) Overconfidence (2) Anchoring (3) Confirmation bias (4) Hindsight bias (5) Gambler's fallacy (6) Herd Behavior. In this investigation, we have included first three of above mentioned judgmental biases of an investor.

To confirm the presence of these psychological factors among investors of ISE, we have conducted this investigation, in which we presented related psychological dilemmas through a questionnaire to investor and recorded how he/she responds to that. From the responses of the investors, we came to know how many market participants are rational.

The main objective of the study isto trace the presence of behavioral biases in the behavior of ISE investors. This study is important because it will be instrumental in explaining the famous volatility of Pakistani stock markets.

\section{Literature Review \\ 1Overconfidence}

The overconfidence is defined as occurring when the confidence judgments are greater than the relative frequencies of the correct answers (Gigerenzer, Hoffrage, \&Kleinbölting, 1991, p. 506). Human being is overconfident creature and overconfidence results in due higher knowledge perception in contrast to reality. This means people are poorly calibrated. They are inclined to strongly believe that their judgments are right, which shows that they are overconfident. Block and Harper (1991) argues that, an overconfident person believe that he know more than in fact he knows and overconfidence is also called "cognitive conceit".

There is lot of research work on how overconfidence effects the decision making or human judgments. Human being, normally unaware of inferential errors they make and don't adjust their subjective confidence according and become victim of overconfidence. Fischhoff (1982) surveyed all literature till that date relating to effects of overconfidence on decision 
making and concluded that overconfidence is harsh reality of the decision making world and cannot be eliminated through carrots and sticks.

Overconfidence is generally high where feedback system is few and far between and indistinct (Fischhoff, Slovic, \& Lichtenstein, 1977). On the basis of this comment by earlier referred authors; one can expect that there will be low tendency of being overconfident among people who forecasts for unambiguous events. Professional forecasters, like the ones, working in stock markets, rely on their better knowledge and experience, and remains less overconfident as compared to common man.

Shefrin (2000) argues that there is fine line between confidence and overconfidence; he supported his argument with demonstration, in which he asked a research group about their driving ability. Between 65 to 80 percent people rated them above average with regard to their driving abilities.

The people in financial market are not different from others. A study was conducted by James Montier (2006), in which 300 funds managers were surveyed, surprisingly everyone consider his/her job performance average or better. The investor generally exaggerates their knowledge, information, experience and skills, when it comes to selecting, purchasing and disposingoff securities. There will be two commonly observed repercussions if the investor is overconfident. Firstly they get involved in bad bets without realizing that they are at informational disadvantage. Secondly they trade too actively.

Investor can be subject to behavioral error of overconfidence and there is relationship between demographics and overconfidence. For example Lundeberg, Fox and Punccohar (1994) and Barber and Odean (2001), is of the opinion that males are more inclined towards overconfidence. The other demographic characteristics like age, investment experience, education, income and wealth influence the subsistence and level of overconfidence (Bhandari\&Deaves, 2005)

In decision making the amount of information and time allowed for analysis results in increase in confidence (Oskamp, 1965; Ryback, 1967).But these two factors does not ensure accuracy in decision making. Therefore Koriat, Lichtenstein, and Fischhoff (1980) comment that, the quantity and quality of informationaffects the level of people's confidence on the decisions made.

\section{Anchoring}

Phung, (2008) defines the heuristic anchoring as the human inclination to connect or "anchor" one's thoughts to a reference point regardless of the fact it may have no logical connection to the decision at hand. An example will make the concept further clear; if one is asked to judge the performance of and other, the anchor of his final judgment may be 
his own performance. On the basis of his own performance, he might underestimate or overestimate one's performance.

Kahneman and Tversky (1974), in their paper "Judgment under uncertainty" explained the anchoring effect with the help of an experiment. In the experiment a wheel bearing the numbers 1 to 100 was spun twice. First time, the wheel landed on no. 10 and second time on no. 60. After spinning the wheel for the first time, the subjects were asked whether the percentage of U.N. membership accounted for by African countries was higher or lower than the number on the wheel. The average of actual estimates given by the subjects for the first was $25 \%$. When the wheel spun for the second time, the same question was asked and the average of estimates of subjects was $45 \%$. One can clearly see that the two random numbers $(10 \& 60)$ obtained by spinning the wheel twice had an anchoring effect on the estimates of the subjects. The subjects have tried in give their estimates closer to the number shown to them by spinning of wheel, whereas there is no logical relationship between the answer of question asked and numbers on which wheel landed.

Anchoring has a role to play in financial world. A number of investors invest in the shares of those corporations who have shown sharp downward trend in recent past. They do so with a misperception in mind that they are buying at discount. In fact they are becoming victim of anchoring effect by anchoring on a latest "high price" that the share has attained (Phung, 2008)

One can see Anchoring effect together with representativeness heuristic and "winner loser effect" concept of Bondt and Thaler. Bondt and Thaler (1985) is of the opinion, if an investor is high on representativeness heuristic scale and a past loser as well; he/she will be overly pessimistic and will become undervalued and vice versa.

Another aspect of anchoring was highlighted by Shefrin (2000); in his view some investors are conservative enough, so that they don't change their forecasts, in accordance with new information. They remained stick to their initial predictions and rely too heavily on earlier information.

The tendency of anchoring will be high, when one is going for/trying new things or novel experience. One can reduce with anchoring by "critical thinking" i-e by not relying too heavily on one or two pieces of information but evaluating the situation from different perspective.

Anchoring is noticeable in behaviors of buyers and sellers at the time of transaction. The price offered or demanded for the first time party influence bargaining and serves as an anchor for the determination of final price. And also the party who make the first offer, normally in a better position to gain a better results from her point of view (Galinsky\&Mussweiler, 2001). 
After conducting an experiment by involving people from financial world, Zielonka (2004) comments that the bubbles and crashes in past stock prices serves as mental anchors. In marketing the consumer buying decision pattern is affected by the price asked in advertisement and functions as an anchor (Biswas\& Burton, 1993). Simonson and Drolet (2004) are of the view that willingness to pay and accept in influenced by anchoring.

\section{Confirmation Bias}

Human tendency, to support that information which conforms their beliefs/ideology or premise is labeled as confirmation bias.It is hard to meet a person, who does not have a preconceived opinion or believe and it's difficult to change this belief or opinion. People identify, select and spread only that information which conforms their initial belief/opinion and set aside the rest information, that might speaks the truth. This tendency in human behavior is knows as confirmation bias. In financial world, especially in investing decision, investors tend to explore and rely on information that supports their initial investment idea and ignores all contradicting information. Investor with confirmation bias see green signal for investment from its selective information and ends up with loss. Nickerson (1998) defines the term confirmation bias in way; it is defined and interpreted in the literature of psychology. In confirmation bias the subjects look for substantiation in a way that supports/conforms their original view/theory/belief or hypothesis.

Commonly people failed to put behind their indigenous thoughts on a particular subject while they are studying/investigating that subject. Such confirmation bias leads them to come up with researches, which comply with their original school of thought and don't reflect true picture. (Jones \&Sugden, 2008).

The players of financial markets are generally considered to be rational optimizer. The underlying reason of this notion is the experience of these players in making transactions in financial markets. If it is so, the question arises that, such way of confirming one's decision is rationally correct? (Jones \&Sugden, 2008).

In 1998 U.S presidential election, Forsythe et al (1992) have studied the students' political bets and forecasts. They found strong evidences of students suffering with confirmation bias. The subjects tend to believe that their presidential candidate (whom they are favoring initially) had won the presidential debate. They also found that people who were not victim of this bias have played a significant role in pushing the political stock market towards efficiency.

People look for confirmation in two ways. Firstly they give preference to the information which conforms their opinion on the issue. For 
instance people tend to assign more weights to their argument supportive information and fewer weights to contradicting information (Baron, 1991). Secondly the confirmation bias comes to surface when people look for "supportive" facts to prove their version. This can be done shaping and asking question that validate the argument instead of violating it (Skov\&Sherman, 1986).

\section{Methods}

In this study primary data is obtained from the individual and institutional investors of Islamabad Stock Exchange (ISE) through questionnaire. The population for this study is all investors (institutional and individual) of Islamabad stock Exchange (ISE). The sample from this population is drawn through convenience and quota sampling and sample size in 117.

The questions in the questionnaire of this study are adapted from two studies (Berneus, H., Sandberg, C. \&Wahlbeck, D., 2008 and Montier, J., 2006). Face validity is established through panel of judges, content validity through content validity ratio (CVR), and construct validity through pretest and post test method. The reliability of instrument is confirmed with Cronbach's alpha and the Kuder-Richardson Formula 20.

The gathered through questionnaires is analyzed with the help of percentages, table and graphs.

\section{Results and Discussion \\ Overconfidence \\ Question 01}

Are you a better driver than average?

a) Yes.b) No.c) No preference.

Table 01

Survey results of question 01

\begin{tabular}{|c|c|c|}
\hline Options & No. of respondents & Percentage \\
\hline Yes & 74 & $63 \%$ \\
\hline No & 29 & $25 \%$ \\
\hline No Preference & 14 & $12 \%$ \\
\hline Total & $\mathbf{1 1 7}$ & $\mathbf{1 0 0 \%}$ \\
\hline
\end{tabular}

\section{Analysis}

It said that human being is an overconfident creature and that is why poorly calibrated, this inference got proved by the response of our target group in above question. $63 \%$ of our target group thinks that they are better driver that others, $25 \%$ thinks otherwise and $12 \%$ has no preference. The above results strongly show the tendencies of overconfidence in investors. 


\section{Question 02}

Are you above average at your job?

a) Yes.b) No.c) No preference.

Table 02

Survey results of question 02

\begin{tabular}{|c|c|c|}
\hline Options & No. of respondents & Percentage \\
\hline Yes & 67 & $57 \%$ \\
\hline No & 35 & $30 \%$ \\
\hline No Preference & 15 & $13 \%$ \\
\hline Total & $\mathbf{1 1 7}$ & $\mathbf{1 0 0 \%}$ \\
\hline
\end{tabular}

\section{Analysis}

The results of second question conform to the responses of first question. Here $57 \%$ of our respondents thinks that they are better in their jobs, $30 \%$ thinks otherwise and 13\% has no preference. Our survey results matches with the results of the study of Montier, conducted in 2006. In which he found that $74 \%$ of the 300 professional fund managers who were included in his target group thinks that they their performance is above average.

The one reason of above shown overconfidence could be prevalence of no or little and inappropriate feedback system in this part of world. That is why the people's perception about their knowledge and skill is high in comparison to reality. The same reasons are provided by Fischhoff, Slovic, \& Lichtenstein, in their study in 1977. The other reason could be the inexperience of investors of an emerging market.

The impact of investor's overconfidence can be seen in following commonly observed trends of the market. Firstly, the investors get involved in bad bets without realizing that they are at informational disadvantage. Secondly, overconfident investor trades too actively. Thirdly, these investors deviate from Bayes' rule when aggregating information. Lastly, they overreact to private signals and underreact to public signals.

Theseabove stated behaviors of an overconfident investor results in irrational decision making, which in turn makes the Islamabad Stock Exchange inefficient.

\section{Anchoring \\ Question 03}

Imagine 100 book bags, each of which contains 1,000 poker chips. Forty-five bags contain 700 black chips and 300 red chips. The other 55 bags contain 300 black chips and 700 red chips. You cannot see inside any of the bags. One of the bags is selected at random by means of a coin toss. Consider the following two questions about the selected book bag. 
(a) What probability would you assign to the event that the selected bag contains predominantly black chips?

(b) Now imagine that 12 chips are drawn, with replacement, from the selected bag. These twelve draws produce 8 blacks and 4 reds. Would you use the new information about the drawing of chips to revise your probability that the selected bag contains predominantly black chips? If so, what new probability would you assign?

\section{Table 03}

Survey results of question 03

\begin{tabular}{|c|c|}
\hline Options & Average of responses \\
\hline Part (a) of question & $46 \%$ \\
\hline Part (b)of question & $55 \%$ \\
\hline
\end{tabular}

\section{Analysis}

The correct answer to the first question is $45 \%$ and the average of responses of the target group is $46 \%$, which understandable and not unexpected. The part (b) is interpreting part of this question and hence important part as well. In this part, the respondents have not used the information given in part (b) and just use their answer of part (a) as an anchor to guess about the answer of part (b).

The correct answer of part (b) is $96 \%$; it means that there are $96 \%$ chances that the selected bag contains predominately black chips. Survey result shows that, the average of answers of the selected respondents is 55\%; which is close to the percentage which they are using as their anchor (46\%, answer of part (a)). So anchoring bias is visible in this case.

\section{Question 04}

1) Please write down the last four digits of your telephone number: number?

2) Is the number of physicians in Islamabad higher or lower than this

3) What is your best guess as to the number of physicians in Islamabad?

Table 04

Survey results of question 04

\begin{tabular}{|c|c|}
\hline $\begin{array}{c}\text { Response to part (1) of the } \\
\text { question (your telephone } \\
\text { number?) }\end{array}$ & $\begin{array}{c}\text { Response to part (3) of the question (Average of } \\
\text { guesses made by the respondents about the } \\
\text { numbers of physicians in Islamabad) }\end{array}$ \\
\hline $\begin{array}{c}\text { Respondents having telephone } \\
\text { numbers below than 6000 }\end{array}$ & 4500 physicians \\
\hline $\begin{array}{c}\text { Respondents having telephone } \\
\text { numbers } 6000 \text { and above }\end{array}$ & 7500 physicians \\
\hline
\end{tabular}




\section{Analysis}

The logic behind this question is to check whether people use their phone numbers as an anchor to guess the number of doctors in Islamabad. The result of the survey shows; yes people used their telephone numbers as anchor. As shown above in table; people, who have telephone numbers above 6000 , think that there are on average 7500 doctors in Islamabad. People with a telephone number of less than 6000 believe that the average numbers of doctors in Islamabad is 4500.

This example clearly shows that target group is using their telephone numbers as anchor to guess the number of doctors in Islamabad. Unconsciously, the respondent uses the answer of part 1 as anchor to provide estimate in third part of the question. That is why the average of their estimates falls around their telephone number.

Such tendencies can be seen in the financial world in which professional investors respond in similar fashion to earnings announcements. They do not adjust their earnings estimates enough to reflect the new information. Resultantly, favorable earnings surprises tend to be followed by more favorable earnings surprises, and unfavorable surprises by more unfavorable surprises (Shefrin, 2000).

\section{Question 05}

A health survey was conducted in a sample of adult males in Islamabad, of all ages and occupations.

Please give your best estimates of the following values:

(a) What percentage of the men surveyed have had one or more heart attacks?

(b) What percentage of the men surveyed are both over 55 and have had one or more heart attacks?

Table 05

Survey results of question 05

\begin{tabular}{|l|l|}
\hline Parts of the question & Average of responses \\
\hline Part (a) & $11 \%$ \\
\hline Part (b) & $26 \%$ \\
\hline
\end{tabular}

\section{Analysis}

Bondt and Thaler (1985) is of the opinion, if a person is high on representativeness heuristic scale it is more likely that he/she will suffer from anchoring bias. So anchoring and representativeness can be checked together, and this is what we are doing in this question. The average of responses of part (a) and part (b) is $11 \%$ \& $26 \%$ respectively. These percentages show noticeable signs of presence of representative heuristic in respondents. 
As results shows in this question, the respondents allowed the representativeness heuristic to prevail over the reasoning. A true myth, that older people are more prone to heart attacks, prevents the respondents from understanding the question in true sense. The respondents used this true myth as anchor to estimate the percentage in pert (b) of the question. That is why the average response of second part of the question is high. Keeping a side the heuristic, it is impossible that part (b) would result in a higher percentage than part (a). The percentage of men having had a heart attack and are over 55 can never be higher than the percentage of the men who have had a heart attack. Same could happen in financial world, a company belonging to a popular industry or group, is not necessarily a good investment avenue.

\section{Confirmation Bias \\ Question 06}

Imagine these are four playing cards laid out in front of you. Each one has a letter on one side and a number on the other. If a card has an E, it should have a 4 . Which cards do you need to turn over in order to see if I am telling the truth?

$[\mathrm{E}][4][\mathrm{K}][7]$

Table 06 Survey results of question 06

\begin{tabular}{|c|c|}
\hline Options & Percentage (\%) \\
\hline $\mathrm{E}$ & $79 \%$ \\
\hline 4 & $75 \%$ \\
\hline $\mathrm{K}$ & $5 \%$ \\
\hline 7 & $13 \%$ \\
\hline
\end{tabular}

\section{Analysis}

The two most obvious choices for this question are [E] and [4]. Nevertheless, the correct cards that need to be turn over are [E] and [7]. The [E] option is pretty clear, because if one turns it over and don't find a [4] on the backside of the card, then he/she was told a lie. If one turns over the [7] and finds the $[E]$ on the opposite side, then he/she can also infer that, he/she was told a lie. The trick of the questions quotes that an "[E] should have a [4], not that a [4] should have an [E]". So turning [4] will not tell you anything and will be non productive exercise.

The above shown result survey tell us that $75 \%$ respondents choose to turn over [4], which is a clear symptom of confirmatory bias - a human tendency to search for information that conforms with our prior belief/knowledge. Karl Popper argues that the only way of checking a hypothesis is to form it and spend whole time to look for evidences to disconfirm it. But it is other way round in our daily working, showing our inclination toward confirmation bias. 


\section{Question 07}

You are about to invest in a specific stock but are still uncertain about whether or not to go along with the purchase. Who are you most likely to discuss your investment plan with?

(a) A co-worker and good friend that you know from previous experience has similar investment preferences as you.

(b) A co-worker that you know from previous experience has different investment preferences than you.

Table 07

Survey results of question 07

\begin{tabular}{|c|c|c|}
\hline Options & No. of respondents & Percentage \\
\hline (a) & 68 & $58 \%$ \\
\hline (b) & 49 & $42 \%$ \\
\hline
\end{tabular}

\section{Analysis}

The higher percentage response of part (a) proves our case i-e investors exhibits irrational tendencies. In this case the investors again showed from their response that they are victim of confirmation bias. In above question, most people are referring to those colleagues and friend who think like them and not to those who have other thinking patterns.

Still a healthy percentage (42\%) wants to discuss with people who have opposite thinking pattern. By doing so, they can have valuable information about new/uncovered aspects of the uncertain situation. So if someone wants to ensure, not to miss the important information, he/she should discuss with people on opposite pole. But, obviously this healthy percentage cannot rule out the majority, which shows tendency of confirmatory bias.

\section{References:}

Kahneman, D., \&Riepe, M. W. (1998).Aspects of Investor Psychology.Journal of Portfolio Management,4, 52-65.

Gigerenzer, G., Hoffrage, U., \&Kleinbölting, H. (1991). Probabilistic mental models: A brunswikian theory of confidence. Psychological Review, 98, 506528.

Block, R. A., \& Harper, D. R. (1991). Overconfidence in estimation: Testing the anchoring-and-adjustment hypothesis. Organizational Behavior and Human Decision Processes, 49, 188-207.

Fischhoff, B. (1982). Debiasing: In D. Kahneman, P. Slovic, \& A. Tversky (Eds.).Judgment under uncertainty: Heuristics and biases, (422-444). City:Publisher

Fischhoff, B., Slovic, P., \& Lichtenstein, S. (1977). Knowing with certainty: The appropriateness of extreme confidence.Journal of Experimental Psychology, 3, 552-64. 
Shefrin, H. (2000). Beyond greed and fear.Harvard Business School Press. Montier, J. (2006).Behaving Badly. Dr. KW Macro Research 2nd February 2006.

Lundeberg, M. A., Fox P. W., \&Punccohar, J. (1994). Highly confident but wrong: Gender differences and similarities in confidence judgments. Journal of Educational Psychology, 86, 114-121.

Barber, B., \&Odean, T. (2001). Boys will be boys: Gender, overconfidence, and common stock investment. Quarterly Journal of Economics, 116, 26192.

Bhandari, G., \&Deaves, R. (2005).Misinformed and informed assets allocation decisions of self-directed retirement plan members. Working paper.

Oskamp, S. (1965).Overconfidence in case-study judgments.The Journal of Consulting Psychology, 29, 261-265.

Ryback, D. (1967). Confidence and accuracy as a function of experience in judgment making in the absence of systematic feedback.Perceptual and Motor Skills, 24, 331-334.

Koriat, A., Lichtenstein, S., \&Fischhoff, B. (1980). Reasons for confidence.Journal of Experimental Psychology: Human Learning and Memory, 6, 107-118.

Phung, A. (2008). Behavioral Finance, Key Concepts- Achoring. Retrived 12.07.2012, from http://www.investopedia.com/university/behavioral_finance/behavioral4.asp Kahneman, D. \&Tversy, A. (1974).Judgment under uncertainty.Science, 23, 1124-1131

Bondt, D. W., \&Thaler, R. (1985). Does the stock market overreact? Journal of Finance, 4, 14,793-805.

Galinsky, A. D., \&Mussweiler, T. (2001). First offers as anchors: The role of perspective-taking and negotiator focus. Journal of Personality and Social Psychology, 81, 657-669.

Zielonka, P. (2004). Technical analysis as the representation of typical cognitive biases.International Review of Financial Analysis, 13, 217-225.

Biswas, A., \& Burton, S. (1993). Consumer perceptions of tensile price claims in advertisements: An assessment of claim types across different discount levels. Journal of the Academy of Marketing Science, 21, 217-229.

Simonson, I., \&Drolet, A. (2004). Anchoring effects on consumers' willingness-to-pay and willingness-to-accept. Journal of Consumer Research, 31, 681-690.

Nickerson, R. (1998). Confirmation bias: A ubiquitous phenomenon in many guises. Review of General Psychology, 2, 175-220. 
Jones, M. \&Sugden, R. (2008).Positive Confirmation bias in the acquisition of information. http://www.springerlink.com/content/ru83312771581275/ retrieved 2008-09-15

Forsythe, R., Nelson, F., Neumann, G., \& Wright, J. (1992).Anatomy of an experimental political stock market.American Economic Review, 21, 11421161

Baron, J. (1991).Beliefs about thinking. In J. F. Voss, D. N. Perkins, \& J. W. Segal (Eds.) Informal reasoning and education, 169-186.

Skov, R. B., \& Sherman, S. J. (1986). Information-gathering processes: Diagnosticity, hypothesis-confirmatory strategies, and perceived hypothesis confirmation. Journal of Experimental Social Psychology, 22, 93-121. 